\title{
78 THE EFFECT OF RUN AND WALK EXERCISE PROGRAMME ON BLOOD LIPIDS AND CHRONIC INFLAMMATION IN SEDENTARY MALES WITH METABOLIC SYNDROME
}

Serkan Hazar, ${ }^{1}$ Muzaffer Koç, ${ }^{2}$ Muhsin Hazar ${ }^{3}{ }^{1}$ Department of Physical Education and Sports, Niğde University, Niğde, Turkey; ${ }^{2}$ Hamamözü Multi-Program High School, Turkey; ${ }^{3}$ Department of Physical Education and Sports, Gazi University, Ankara, Turkey

\subsection{6/bjsm.2010.078725.78}

The aim of the study was to determine and evaluate the effect of 8-week run-walk exercises on blood lipids and chronic inflammation in sedentary males with metabolic syndrome. 13 volunteer males with metabolic syndrome were chosen for the study who applied to participate. Inclusion criteria were diagnostic criteria for metabolic syndrome of National Cholesterol Education Program (ATP III). Blood samples were taken before and after exercise programme. Blood lipids and $\mathrm{C}$ reactive protein (CRP) levels were determined by an autoanalyser (Cobas Integra 800; Roche, Mannheim, Germany). Wilcoxon signed rank test was used for data evaluation and significance level $\alpha$ was set at 0.05 . Participants performed run and walk for an hour 3 days a week for 8 weeks. In the first week, exercise started for $4 \mathrm{~km}$ in an hour, in the later weeks exercise continued for $6 \mathrm{~km}$. After the exercise programme, a significant decrease was observed in the weight, BMI and waist circumference of the participants, whereas the decreases in cholesterol, LDL and triglyceride levels of the participants were statically insignificant. On the other hand, there was statistically significant increase in HDL level. After the exercise programme, decrease of CRP values was statically insignificant. As a result, the 8-week run-walk exercises positively affected some anthropometric characteristics as weight, BMI and waist circumference. But it did not affect blood lipids and chronic inflammation. This exercise was normally expected do make metabolic effect as well as anthropometric effect in a positive way. However, the 8-week run-walk exercise programme can be said to have been not long enough for the participants with metabolic syndrome to make a significant effect. 